KIPPING AND CLARKE : $a$-AMINO- $\beta$-METHYLHYDRINDENE. 913

\title{
LXXXIX.—a-Amino- $\beta$-methylhydrindene.
}

By Frederic Stanley Kipping and George Clarke, A.I.C.

Tre method already employed with such success for the synthesis of the cyclic ketones, a-hydrindone (Kipping, Trans., 1894, 65, 680), a-ketotetrahydronaphthalene (Kipping and Hill, Trans., 1899, 75, 144), and pheno- $\alpha$-ketoheptamethylene (Kipping and Hunter, Trans., 1901, $79,602)$, from the chlorides of aliphatic acids containing aromatic substituents has now been extended to the preparation of substituted ketones, and in the present paper the authors describe the results of experiments on the intramolecular condensation of benzylmethylacetic chloride und er the influence of aluminium chloride. 
The $\beta$-methyl-a-hydrindone, which is thus produced,<smiles>CC(C)[C@H](C)C(=O)OC1CCCC1C(=O)O</smiles>

contains an asymmetric carbon group, and consequently the synthetical compound is composed of equal quantities of enantiomorphously related components. When, therefore, it is combined with hydroxylamine and the resulting oxime reduced to the base $\beta$-methyl-a-hydrindamine ( $\alpha$-amino- $\beta$-methylhydrindene), a homologue of hydrindamine, the product will contain two asymmetric carbon groups, a new one having been formed during the reduction of the oximino- to the aminogroup,

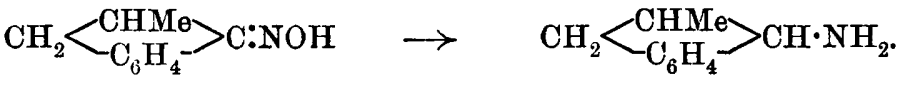

From theoretical considerations, then, the base should exist in four optically active modifications, namely :

$\begin{array}{cccc}\text { I. } & \text { II. } & \text { IlI. } & \text { IV. } \\ + & - & + & - \\ + & - & - & +\end{array}$

and these should give rise to two different externally compensated compounds formed by the admixture of I and II, and of III and IV respectively.

When combined with optically inactive acids, the synthetical base should therefore give two series of salts, and, as will be shown later, two hydrochlorides are in fact produced, but in very unequal quantities; this formation of unequal quantities of the two $d l$-bases is, of course, what might have been expected, inasmuch as the synthesis of the second asymmetric carbon group occurs in a compound which is already enantiomorphous.

The principal object in preparing these bases was to study their behaviour with optically active acids, and to obtain, if possible, isomeric partially racemic salts corresponding with the hydrindamine compounds (Kipping, Trans., 1900,77, 861); as one of the authors was unfortunately unable to continue the work, the thorough investigation of some salts of the two bases is described in the following paper.

$\beta$-Methyl- $\alpha$-hydrindone has been previously prepared by von Miller and Rhode (Ber., 1890, 23, 1888) by heating benzylmethylacetic acid with concentrated sulphuric acid at $150^{\circ}$; this method, however, was found to be unsatisfactory, as the yield was very poor compared with that obtained with the aid of aluminium chloride. 


\section{EXPER IMENTAL.}

Benzylmethylacetic acid is conveniently obtained from benzylmethylmalonic acid by eliminating carbon dioxide, or by the acid hydrolysis of ethyl benzylmethylacetoacetate; the acid boils at $160-161^{\circ}$ under a pressure of $17 \mathrm{~mm}$., and solidifies when cooled to a mass of colourless crystals melting at $37^{\circ}$, as stated by Conrad and Hodgkinson (Annalen, $1878,193,312)$.

Benzylmethylacetic chloride is prepared with the aid of phosphorus pentachloride in the usual manner, a vigorous action taking place; it is a moderately mobile liquid, fumes slightly on exposure to the air, and has a particularly disagreeable and penetrating odour.

\section{Preparation of $\beta$-Methyl-a-hydrindone.}

The action of aluminium chloride on benzylmethylacetic chloride and the amount of methylhydrindone produced depend entirely on the conditions of the experiment. The action is not so vigorous as that which occurs in the preparation of hydrindone, and, probably in consequence of this, the formation of tarry matter is not nearly so great.

In the first experiments, the acid chloride was dissolved in five times its volume of light petroleum (b. p. $60-80^{\circ}$ ), and three parts of aluminium chloride employed to five of the acid chloride; no evolution of hydrogen chloride occurred, however, and not until the mixture had been heated for some time did any action begin. A colourless, crystalline compound, non-volatile in steam, was then formed, but as this substance, doubtless an aluminium compound, was not decomposed, giving the ketone, when boiled with weak alkalis, it was not further investigated. After further experiments, the following were found to be the best conditions for the production of the desired ketone. The acid chloride (10 grams), dissolved in from 6-7 times its volume of light petroleum (b. p. $90-100^{\circ}$ ), is treated with finely powdered aluminium chloride (10 grams), and the mixture gradually heated on the water-bath until the petroleum begins to boil, the flask being vigorously shaken in the meanwhile. At the end of fifteen minutes, the evolution of hydrogen chloride, which has previously been very vigorous, begins to slacken, and in about twenty minutes the reaction may be considered to be complete. After cooling, water is cautiously added, and the light petroleum distilled off in a slow current of steam; the ketone is then distilled in steam, the distillate rendered alkaline with sodium carbonate, and the ketone extracted with ether. The product remaining after evaporating the ether is a colourless oil, 
having the strong odour of peppermint mentioned by von Miller and Rhode; the yield is $70-80$ per cent. of the theoretical.

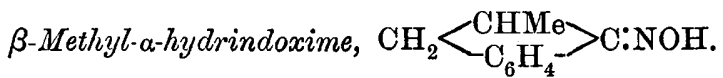

This oxime is prepared in the usual manner, the ketone being treated with hydroxylamine hydrochloride and excess of caustic potash in aqueous methyl-alcoholic solution; after 24 hours at the ordinary temperature, most of the alcohol is evaporated off on the water-bath, and the mixture is poured into water, when the oxime separates as a red, viscid oil, which very slowly solidifies to a hard cake.

The crude product, crystallised either from aqueous methyl alcohol or light petroleum, is thus obtained in well-defined, apparently octahedral crystals melting at about $104^{\circ}$; it is readily soluble in alcohol, ether, and chloroform, but only sparingly so in cold light petroleum, being almost insoluble in water and alkalis. The further investigation of this compound showed that it consisted of a mixture of isomerides which, however, were not isolated; samples of the material, roughly purified by one crystallisation, were employed for the preparation of the base.

$$
\beta \text {-Methyl-a-hydrindamine, } \mathrm{CH}_{2}<\mathrm{C}_{6} \mathrm{H}_{4}>\mathrm{CH} \cdot \mathrm{NH}_{2} \text {. }
$$

- $\beta$-Methylhydrindoxime is readily reduced with the aid of sodium amalgam and aqueous acetic acid; in order to avoid waste of amalgam, the solution should be kept cool and stirred continuously, the amalgam being added in small quantities at a time. Whon only a slight turbidity is formed on the addition of water, the solution is decanted, and any unchanged oxime distilled off in a current of steam; the base is then liberated by adding excess of caustic potash and the steam distillation continued.

The $\beta$-methyl-a-hydrindamine then passes over as a colourless oil, which has a strong odour not unlike that of aniline and is only sparingly soluble in water; it is a strong base, and on exposure to the air it is converted into a crystalline substance owing to absorption of carbon dioxide.

\section{The Two dl- $\beta$-Methyl-a-hydrindamines.}

As pointed out above, two bases should be formed by the reduction of the oxime, but not necessarily in equal quantities. It was, however, a matter of some doubt whether the difference in solubilities of their salts with optically inactive acids would be such as to render possible a separation of these salts by fractional crystallisation. 
With the view of ascertaining whether or not this was the case, the mixture of bases and water obtained by distillation in steam was treated with hydrochloric acid and the resulting product systematically crystallised from water. The first and several successive deposits consisted of long, silky needles, which were apparently homogeneous, but subsequent fractions were obviously mixtures and contained, in addition to the long needles, small, nodular masses of smaller and illdefined crystals. After further recrystallisation, the hydrochloride separating in long needles was obtained in an apparently pure condition; it had not a definite melting point, but decomposed at about $250^{\circ}$. This compound is referred to as the hydrochloride of the $A$-base. The hydrochloride crystallising in nodular masses, which is referred to as the salt of the $B$-base, was probably only obtained in an impure condition; it decomposed at about $225^{\circ}$.

\section{The Platinichlorides of the Two dl-Bases.}

In order to prove that the hydrochlorides just described are derived from isomeric bases, analyses of the platinichlorides were made. The platinichloride prepared from the hydrochioride of the $A$-base crystallised from water in lustrous, yellow plates decomposing at about $192^{\circ}$; a sample which had been crystallised twice from water and air-dried until constant in weight was analysed, with the following results :

$$
\begin{aligned}
& 0.3457 \text { lost } 0.0157 \text { at } 100^{\circ} . \mathrm{H}_{2} \mathrm{O}=4.54 . \\
& 0.2461,0.0121 \text { at } 100^{\circ} . \mathrm{H}_{2} \mathrm{O}=4.91 . \\
& 0.3284 \text { anbydrous salt gave } 0.0905 \mathrm{Pt} . \quad \mathrm{Pt}=27.55 . \\
& \left(\mathrm{C}_{10} \mathrm{H}_{13} \mathrm{~N}\right)_{2}, \mathrm{H}_{2} \mathrm{PtCl}_{6}, 2 \mathrm{H}_{2} \mathrm{O} \text { requires } \mathrm{H}_{2} \mathrm{O}=4.81 ; \mathrm{Pt}=27.68 \text { per cent. }
\end{aligned}
$$

The platinichloride prepared from the hydrochloride of the $B$.base was rather more soluble in water than the derivative of the $A$-base, and separated in lustrous, yellow plates decomposing at about $202^{\circ}$; the air-dried salt did not lose in weight when heated at $100^{\circ}$.

$$
\begin{aligned}
0.4304 \text { gave } 0.1190 \mathrm{Pt} . \quad \mathrm{Pt} & =27.64 . \\
\left(\mathrm{C}_{10} \mathrm{H}_{13} \mathrm{~N}\right)_{2}, \mathrm{H}_{2} \mathrm{PtCl}_{6} \text { requires } \mathrm{Pt} & =27.68 \text { per cent. }
\end{aligned}
$$

\section{The Benzoyl Derivatives of the Two dl-Bases.}

As it was difficult to tell whether the hydrochlorides were pure or not, that is to say, whether the two $d l$-bases had been completely or only partially separated, the benzoyl derivatives were prepared from samples of the two hydrochlorides by the Schotten-Baumann method. The crude products, which were precipitated in the form of colourless powders, were purified by crystallisation from alcohol.

VOL. LXXXIII. 
The benzoyl derivative of the $A$-base was thus obtained in long, silky needles melting sharply at $169^{\circ}$, and its melting point was not changed on repeated crystallisation; it was only sparingly soluble in cold alcohol, but dissolved freely on warming.

The benzoyl derivative of the $B$-base crystallised in short needles, and was apparently much more readily soluble in alcohol than the derivative of the $A$-base; it began to melt at about $135^{\circ}$ and liquefied completely at about $138^{\circ}$, but when fractionally crystallised its melt. ing point did not remain corstant and it was doubtless a mixture of the two isomerides. Attempts to isolate a pure compound from this mixture were not successful, but the above experiments seemed to establish the existence of two externally compensated methylhydrindamines.

The cost of part of the materials used in this work was covered by a Government Grant from the Royal Society, for which the authors desire to record their thanks.

UNIVERSITY CoLlege,

Nottingham. 